\title{
A Review of Parametric and Physiographic Approaches Land Classification for Land Evaluation and Land Use Planning
}

\author{
*Santun R.P. Sitorus \\ Department of Soil Science and Land Resource, Faculty of Agriculture, Bogor Agricultural University (IPB), \\ Meranti Street, IPB Dramaga Campus Bogor 16680, Indonesia. Phone/ Fax : (+62 251) 8422322 \\ Email: santun_rps@yahoo.com; santun_rps@apps.ipb.ac.id
}

${ }^{*}$ Corresponding Author, Received: October 31, 2018, Revised: November 25, 2018, Accepted: December 5, 2018

This is an open acces article distributed under the Creative Commons 4.0 Attribution License, wich permits unrestricted use, Distribution, and reproduction in any medium provided the original work is properly cited @2017 by author and Universitas Negeri Padang

\begin{abstract}
Knowledge of physical characteristics of land is fundamental for rational land evaluation and land use planning, both in developed and undeveloped regions. A review of two land classifications, parametric and physiographic approaches, is carried out. The parametric approach classifies on the basis of selected land attributes determined by land use or uses in question. Its employment may range from general purpose surveys which are considering many attributes, to classification on the narrower basis for special purposes. The physiographic approach, on the other hand, classifies land rather than its specific attributes. Each land unit identified in this way is therefore considered to be relatively homogeneous in overall characters. Both approaches have had varying merits depending on the goal and circumstances of the land evaluation. On a detailed study required by most practical purposes, both approaches theoretically meet the requirements of land classification. Of both approaches, it was concluded that physiographic approach had the advantage of being rapidly implemented whereas, the parametric approach, whilst slower in use and applicable only in localized studies, yielded more reliable results. In reality, however, the distinction between both approaches is not so clear-cut because they can be combined with advantage. Their advantages and disadvantages relative merits also are assessed related to three problems of land classification: (1) complexity of land, (2). extent of land-units, and (3) associations of land-units. The two approaches are really not alternatives and can, in fact, be combined with profit, since the relative advantage of each varies with circumstances. The physiographic approach offers a possibility on the more rapid survey at relatively low cost, as needed in most undeveloped regions. Its reliability is consistent for reconnaissance investigation and, with moderately close sampling, for semi-detailed surveys. It has an additional advantage of enabling a survey with diverse specialists. For a detailed survey, however, greater precision and reliability of the parametric approach is preferable. In practice, therefore, both methods are best combined to reinforce each other.
\end{abstract}

Keywords: The Complexity of Land, Extent of Land Units, An Association of Land Units, Comparative Summary, Advantages and Disadvantages

\section{Introduction}

Knowledge of physical land characteristics is fundamental for rational land use planning, both in developed and least developed regions. All developed regions already have such basic knowledge about the land, although further surveys may be needed to obtain more detailed information when particular development programmes are required. Such surveys have been introduced in Canada, for example, using a 'landscape' approach for large-scale mapping of soils needed for master planning in the Ottawa-Carleton area (Dumanski et al., 1979; Hermon, 2017). With increasing controversy over the conversion of agricultural land to other uses, Agricultural Land Evaluation and Site Assessment (LESA) system have been introduced to help State and local officials in the United States to assist decision making in land use planning. The LESA 
system was applied as an alternative for previous land capability classification and land inventories system which was considered to be of little value to local planners in determining remaining agricultural fields (Wright et al., 1983; Dunford et al., 1983). Undeveloped regions, which generally have little or no information on land resources, pose radically different problems from those in developed ones. Due to this lack of information, easily applied, rapid surveys are needed to provide quick results when development planning has to be carried out in remote, inaccessible areas. Two main approaches to this problem may be singled out.

First, land can be considered from the point of view of the uses envisaged, a list of relevant factors and the classification limits can be devised for each of these, and then a means sought to examine and apply them in particular areas (Hermon, 2014). As an illustration, semi-arid land may be regarded as becoming more suitable for arable crops as factors such as relief, stoniness and soil salinity decrease, and so each of these factors should be classified into acceptable and unacceptable classes which then need to be delimited as favourable and unfavourable combinations on maps and aerial photos or other remote sensing imagery of the area (Hermon et al., 2018). This approach will tend to be favoured when only a restricted number of specific land uses are to be considered. As the number of envisaged land uses is increased, for instance, to include diverse information about such things as irrigation potential, soil erodibility, etc., the variables needed for evaluation multiply, become more complex, and the difficulty of identifying them spatially over the area in question increases greatly. The greater the number of variables needed, and the greater the number of classification units within each, the more complicated becomes an already difficult task. There will be a tendency to start with the detailed measurement of small areas in relation to the types of land use envisaged, leaving to a later phase the problem of extrapolating many measurements into the total study area. This system is termed the 'parametric approach' or, as Zonneveld (1979) called it, the 'separationist approach'.

A second approach may be favoured as the envisaged number of possible land uses is increased. If the information is required over a wide range of practical applications in development planning, such as in agriculture, engineering, etc., the number of relevant criteria becomes so great as to defy simple analysis. Consequently, a 'physiographic' approach to land classification-commonly with a landform framework - is utilised to identify natural areal units. Zonneveld (1979) also called this the 'holistic' approach.

\section{The Parametric Approach}

This approach classifies land on the basis of selected land attributes (Mabbutt, 1968), the selection being determined by the land-use or uses in question. It is employed when an individual aspect of the land is more important than the overall character of the land as a whole. However, its employment may range from general purpose surveys considering many attributes, to classification on a narrower basis for special purposes. A more specific interpretation of the parametric approach has been described by Require (FAO 1974). This involves the selection of soil properties which are evaluated and awarded scores; then these properties by means of the scores are substituted into mathematical formulae to produce a final 'index of performance'. The resultant values can be used themselves for assessment purposes, or alternatively to rank soils in order of agricultural value. Another widely quoted method is the 'stories index' (Storie, 1950; Storie, 1954) which is obtained by multiplying scores for selected variables. It was developed primarily to assist with land assessment for taxation purposes in California. Other parametric methods using the 'stories index' principle are discussed by Olson (1974) and Vink (1975), and Weiers (1975) has summarised a comparable method of assessment used in Germany. Mapping for the parametric classification approach can be done by constructing a map on which contours, or 'isopleths' (boundaries), indicate the distribution of a number of classes each representing a particular range (defined or implied) of several properties (Beckett and Bie, 1978). According to King (1970) progress in land system analysis needs distinct, preferably genetic and quantitative or semi-quantitative descriptions and classification. In an attempt to fulfil this need, the following parameters are used to classify land systems: process, altitude, relief, dominant geology, drainage pattern, stream frequency, characteristic plan-profile, geomorphic position, dominant facet, characteristic facet, characteristic variant and land zone. Land units delimited by a number of criteria are likely to have uncertain boundaries. At least two procedures can be employed to resolve this uncertainty. Firstly, by superimposing maps of the different attributes, a composite boundary can be selected as a compromise between them. Secondly, the attributes can be ranked in order of importance, with the most important one being used to define the land 
unit boundaries and the rest forming sub-divisions within the land units. The parametric approach has the advantage that quantifiable criteria can be selected, thus facilitating objectivity and reliability of data and a high reproducibility and accuracy. Problems inherent in the approach include the choice of attributes, the delimitation of their classes, the time is taken to quantify them and carry out the classification over the study area, and the likelihood that each classification is specific only to a particular land use.

\section{The Physiographic Approach}

This approach classifies 'land' rather than its specific attributes, on the assumption that an area of relatively uniform physiography is associated with relative uniformity of other major environmental factors such as ground climate, soil properties, plant habitat conditions, etc. Each land unit identified in this way is thus considered to be relatively homogeneous in overall character. The approach is particularly appropriate when evaluation of the terrain as a whole is required. The physiographic land classification has received increasing practical attention for land evaluation purposes following two approximately contemporaneous events: the development of the concept of physiographic units as basic subdivisions of landscapes, and growth in the use of remote sensors, particularly aerial photographs.

In the last fifty years, aerial photographs have become widely available, with equipment and techniques for their interpretation becoming much improved (Lillesand and Kiefer, 1979). This has greatly facilitated the identification of physiographic units and their relatively speedy mapping. Rapid growth in the use of physiographic land survey using aerial photography occurred in Rusia, Australia, Canada and other areas in urgent need of land development (Zonneveld, 1979). There has been a corresponding application of aerial photography for the resource by Soetanto (1978). Remote sensors, and particularly the use of aerial photo interpretation, are considered to be essential tools for speedy work in such surveys.

\section{Physiographic Basis for Land Classification and Mapping}

From early times the influence of davisian geomorphology (Davis, 1899; Hermon, 2001; Hermon, 2010) has been manifest in many studies of physiographic mapping. These studies, based on consideration of landform genesis (see references in Wright, 1972 and Mitchell, 1973) had major limitations despite their substantial qualities (see also Mabbutt 1968) which became more obvious as the need arose for more precise definitions of land use and terrain relationships to meet the requirements of present-day land potential assessment and land use planning. Many of the physiographic divisions recognised were large, with imprecisely defined boundaries, and hence, in spite of any genetic unity, they were internally very complex. It is weakness inherent in any system in which lower units are derived from higher ones, that generalizations are transmitted downwards (Mabbutt, 1968).

Consequently, some have sought to remove these fundamental limitations by substituting the concept of an integrated landscape for the genetic approach. This was developed independently for different areas and purposes and rests upon the principle that units of land, however, defined, recur in the landscape in recognisable patterns. The concept was initiated by Bourne (1931) with respect to forestry and agricultural resources. He defined a 'site' as an area which appears, for all practical purposes, to provide throughout its extend similar local conditions as to climate, physiography, geology and soil. Bourne clearly envisaged that a site defined physiographically would possess similar soils and that these would differ from those of other sites. Recurring associations of sites formed 'regions' which, because of greater internal variations, had diminished homogeneity. From this pioneering study a number of physiographic classification have been evolved (e.g. Unstead, 1933). Similarly, Milne (1935) suggested the 'catena' concept arising from his studies of East African soils. This was based on recognition of soil-landform patterns, in which spatial groups of soils, or catenas, while they fell wide apart in a natural system of classification on account of fundamental genetic and morphological differences, were yet linked in their spatial occurrence by conditions of topography and were repeated in the same relationship to each other wherever the same conditions arose.

Linton (1951) equated Bourne's sites with his 'ultimate units of relief', 'flats' and 'slopes'. A few such sites recurring in association with each other would constitute a region. Such a region itself would result from uniform physiographic processes operating on an area of uniform rock and degree of relief but would be 
defined by the association of sites which characterised it. The integrated landscape approach recognises that the character of a region is the result of a combination of interrelated factors such as climate, parent material, relief, natural drainage, soils and vegetation. Consideration of these environmental determinants separately, in isolation from one another, is of limited value; they must be studied in their interactions in order to obtain an adequate appreciation of a region as a whole.

The landscape, therefore, is viewed as a series of physiographic regions each having definitive characteristics which serve to mark it off from other regions. Any area can be divided into a limited number of these regions. What is of great importance to be considered is that such regional differentiation should be based on a consistent, objective methodology and that the regions so defined occur in recurrent spatial patterns. The similar notion of a region being characterised by a repeating pattern of a few, more-or-less homogeneous physiographic units underlies the reconnaissance land surveys of the Commonwealth Scientific and Industrial Research Organisation (C.S.I.R.O.) in Australia (Christian and Stewart, 1953; Christian, 1958). These surveys are based on the concept of 'land units' and 'land systems', the land system being: "an area or group of areas throughout which there is a recurring pattern of landform, soils and vegetation" (Christian and Stewart, 1953). Surveys based on those of the CSIRO have since been carried out in many other areas. The objective of these surveys, according to Christian (1958) was to describe, classify and map, and assess the land use, developmental possibilities and technical problems of large areas of the country about which there was relatively little recorded scientific information. These surveys produced maps at scales of 1:250.000 and $1: 1$ million.

As many of the areas studied were very large, considerable emphasis was placed on the use of aerial photography in correlating air photos with sampled ground characteristics. Detailed mapping of individual terrain characteristics was not feasible, and this led to the mapping of complexes of terrain rather than the separate mapping of individual characteristics. From this arose the concept of land systems and their constituent descriptive units, land units. The description and classification of the land systems of a region constituted the first stage of the study programme. This obtained information provided a framework into which more detailed data could later be fitted. The assessment of land use potentialities represented a second stage of the programme. This phase of work was regarded as a continuing process and, as new knowledge became available, always subject to revision. In the initial assessment, the significance of observable characteristics of the environment is interpreted by deduction or by comparison with known responses in other comparable areas.

There are, of course, some limitations to what can be gained from some of these applications. Christian (1958) points out that the best that can be expected from the initial assessment in new areas is a broad statement on the likely scope for land use and it's most obvious problems which can be tested by experiment. It will serve to separate those areas worthy of more immediate and intensive study from those which could well be disregarded for the time being. In the foregoing surveys, as in most studies of the physical characteristics of land, the land types or patterns of land recognised are not intended to provide the final answers to regional potentialities but rather to provide a scientific basis upon which subsequent investigations and experiments can be planned or carried out. In Britain, Beckett and Webster (1965) developed a terrain classification method for the Military Engineering Experimental Establishment (MEXE) using physiographic subdivision for land evaluation for engineering purposes. The physiographic units are 'Recurrent Land Pattern (RLPs)' and 'facets'. The RLP, in fact, corresponds to the land system of the CSIRO. This method has been used for predicting site conditions is arid areas (Perrin and Mitchel, 1969).

The landscape unit approach has also been developed in Russia (Vinegradov et al., 1962), Poland as physical-geographical regionalisation (Bartkowski, 1968) and Canada as biophysical land classification (Ginbarzevsky, 1978). It is clear that there is a close similarity of approach to integrated terrain classification despite the different areas, disciplines, times and scales involved. All methods have the implicit or stated assumption that the simplest land unit has low variability of the basic elements in the physical environment, and seek to identify their spatial patterns of occurrence within a hierarchy of increasingly more complex regions, usually derived from air photograph interpretation. A basic difficulty is that the more detailed the definition and the more homogeneous the properties of the units required, the harder it becomes to recognise them on aerial photographs. 
Numerous attempts have been made to classify land using the physiographic approach. Mitchell and Perrin (1966), for instance, have divided hot desert terrain into a relatively small number of recurring physiographic units, termed land facets and land systems, which were recognisable on aerial photographs. Van Zuidam and Van Zuidam-Cancelado (1979) have demonstrated the applications of this approach for various purposes, including agricultural land evaluation. In this case, land classification and analysis were done in such a way that the land units selected are defined according to their agricultural potential. Sitorus (1983) have decided four land complexes delimited using a geomorphological site-analysis approach to land classification for an area near Alcantarilla in Murcia Province, S.E. Spain for Soil variability study including for land evaluation.

\section{Physiographic Approach Land Classification Review}

Eight examples of physiographic classification are summarized in comparative form in Table.1, on which the following review is largely based. Table 1 shows that almost all of them utilize the method of Subdivision, implemented largely on the basis of air photo interpretation, and designed for use primarily at the reconnaissance level. The site-analysis method (Wright, 1972; Wright, 1973) and the ITC terrain classification (van Zuidam and van Zuidam-Cancelado, 1979; Oktorie, 2017) involve a combination of physiographic characteristics, such as slope gradient, which is assumed to reflect a corresponding degree of homogeneity of other, though not all, land characteristics. This is the physiographic element of the approach. The parametric element involves the selection of measured variables to characterize and classify the units in term of landform, soil and vegetation properties which are considered most relevant to land use purposes.

Most of the physiographic systems use a predominantly sub divisive method in their classification approach, the exception being the site analysis method (Wright, 1972) which is based on an agglomerative process of the construction. Likewise, most of the methods reviewed have air photo interpretation as a major tool in their classification system, not simply as a means of extrapolation ground-truth data but as the basis of identifying and delineating subdivision in the system which then provides the framework for collecting the data to be used to describe those units. Site analysis, however, depends upon intensive ground sampling to identify units and to build an aggregative classification system from below, with sites, the primary taxonomic units, being delimited in the field, and with air photo interpretation being used to facilitate sampling design and the extrapolation of the site data.

Most of the methods have broadly comparable terminologies. For instance, in the land systems of CSIRO, the Canadian Bio-physical scheme, and the UK Land Resource Division are closely similar conceptually to other terms such as the Soviet Urochishcha, the MEXE Recurrent Landscape Patterns, the PUCE and ITC terrain patterns and the land complexes of site analysis. Thus each of these various mapping units is equivalent in being regarded as a recurring pattern of landform, rock, soil and vegetation. Working scales as presented in the eighth column of Table 1 derive from 'working definitions' in which 'detailed', 'medium', and 'broad' are defined as an intensity of ground sampling appropriate to the production of maps at a scale of up to 1:20,000, greater than 1:20,000 to 1:250,000, and greater than 1:250,000, respectively. Unlike soil surveys where there is a fairly rigorous relationship between working scales and map scales, such relationships may not be so clear in many physiographic surveys hitherto, which have depended greatly upon air photo interpretation and with the amount of groundwork not always stated explicitly. Most of the methods have been applied as reconnaissance surveys, though some have been employed at varying scales or levels of intensity. Beyond this, however, they vary in their main purpose. Some were initially for military purposes (MEXE), others for land resource inventory (CSIRO, Soviet System, Site analysis, Canadian Bio-physical scheme), or agroforestry (UK Land Resource Division system), or engineering (PUCE), or multi-purpose (ITC).

\section{Comparison Of Parametric And Physiographic Approaches}

Of the two major approaches of land classification parametric and physiographic, it was concluded that the physiographic approach had the advantage of being rapidly implemented, whereas the parametric approach, whilst slower in use and applicable only in localized studies, yielded more reliable results. In 
reality, however, the distinction between the two approaches is not so clear-cut because they can be combined with advantage. Having outline both the parametric and physiographic approaches, their relative merits will now be assessed in relation to the three problems of land classification identified. Those are:

\section{Complexity of Land}

The parametric approach simplifies the complexity of the land by selecting only those attributes of relevance to the particular land use in question. This is advantageous in more specifically-defined land evaluation. The physiographic approach, in classifying land as a whole, retains its inherent complexity in the land units identified. This makes it possible within the land unit framework to assess land character as a whole over large areas for either reconnaissance or moderately intensive land use.

\section{Extent of Land-Units}

The parametric approach potentially allows for greater precision of boundary definition, although problems occur when a large number of variables are chosen and found to vary in different ways and at different scales. With the physiographic approach, it may be difficult to form a precise definition of land unit boundaries because some subjective assessment is inevitably involved. Both approaches, however, have difficulty in defining boundaries in the common situation of gradual change in land characteristics. Conversely, both approaches are more readily applied where there is an abrupt change in land character.

3. Associations of Land-Units

The hierarchical nature of the physiographic approach has advantages in that land units can be recognised at differing scales in terms of the patterns of recurring smaller land units they contain. There is no such hierarchic pattern inherent in the parametric approach.

The main advantages of the parametric approach compared to the physiographic approach are: it is more quantitative and less dependent upon subjective interpretation of landforms; it is better suited to the increasing use of electronic data-handling, such as by computers; it leads to a more flexible system, providing land units which are more easily modified in the light of expanding knowledge. Its main disadvantages are: it is commonly difficult to decide on the most appropriate variables and their class limits for any given land use; extrapolation of measured attributes beyond their place of measurement is problematical other than by reference to the physiographic analogy of landforms recognized on aerial photographs, hence more detailed sampling is needed than in a physiographic approach-which necessitates more ground measurement and greater detail in mapping each variable. As information on most attributes tends to be scanty in undeveloped regions, maps must either be based on slow and costly ground surveys, which tend to be restricted to small areas or else to be at scales that are too broad to be of much practical use for most development planning purposes.

\section{Conclusion}

It is concluded that the two approaches have varying merits depending on the goal and circumstances of the land evaluation. At the detailed scale of study required for most practical purposes, both approaches theoretically can meet the requirements of land classification. The two approaches are really not alternatives and can, in fact, be combined with profit since the relative advantage of each varies with circumstances. The physiographic approach offers the possibility of the more rapid survey at relatively low cost, as needed in most undeveloped regions. Its reliability is consistent for reconnaissance investigation and, with moderately close sampling, for semi-detailed surveys. It has the additional advantage of enabling the survey work of diverse specialists to be combined into a single operation. For a detailed survey, however, the greater precision and reliability of the parametric approach are preferable. In practice, therefore, the two methods are best combined to reinforce each other. 


\section{References}

Aitchison, G.D. and Grant, K. (1967). The P.U.C.E. programme of terrain description, evaluation and interpretation for engineering purposes. Proc. 4th Regional Conf. Africa. Soil Mechanics and Foundation Engineering, Cape Town, 1,1-8.

Bartkowski, T. (1968). Methods of dividing Poland into microregions for requirements of appraisal of geographic environment. Geographia Polonica. 14, 217-221.

Beckett, P.H.T., Bie, S.W. (1978). The use of soil and land systems maps to provide soil information in Australia. CSIRO Div. Soils Technical Paper No. 33 Australia.

Beckett, P.H.T, Webster, R. (1965). A classification system for terrain. Report No. 872. Military Engineering Experimental Establishment. Christchurch, Hampshire, England. 28 pp + Appendices A-D.

Bourne, R. (1931). Regional Survey and its relation to stocktaking of the agricultural and forest resources of the British Empire. Oxford Forestry Memoirs No. 13. Clarendon Press, Oxford. 16pp + plates

Christian, C.S. (1958). The Concept of land units and land systems. Proceedings of the ninth Pacific Science Congress, Bangkok. 20, 74-81.

Christian, C.S. and Stewart, G.A. (1968). Methodology of Integrated Surveys. Aerial Surveys and Integrated Studies. Proc. Of Toulouse Conf. UNESCO, Paris. pp. 233-280.

Christian, C.S. and Stewart, G.A. (1953). General Report on Survey of Katherine-Darwin region, 1946. C.S.I.R.O, Land Research Series No.1.

Davis, W.M. (1899). The geographical cycle. Geographical Journal 14,481-504.

Dumanski, J., Marshall, I.B. and Huffman, E.C. (1979). Soil capability analysis for regional land use planning - A Study of the Ottawa urban fringe. Can. J. Soil Sci. 59,363-379.

Dunford, R.W., Roe, R.D., Steiner, F.R., Wagner, W.R., Wright, L.E. (1983). Implementing LESA in Whitman county, Washington. Journal of Soil and Water Conservation. 38(2), 87-89.

FAO (1974). Approaches to land classification. Soils Bull. No. 22, FAO, Rome. 120pp.

Gimbarzevsky. P. (1978). Land Classification as a base for Integrated of Renewable Resources Inventories. Proceedings National Workshop on Integrated Inventories of Renewable Natural Resources, Tucson, Arizona, Jan. 8-12, 1978. pp. 169-177.

Hermon, D. 2001. Studi Kontribusi Penggunaan Lahan dan Vegetasi Terhadap Karakteristik Epipedon. Tesis Magister. Program Pascasarjana Universitas Andalas Padang.

Hermon, D. 2010. Analisis Spasial Tingkat Bahaya Longsor Toposequent Marapi Bagian Barat Kab. Tanah Datar. Jurnal Geografi. Vol. 2.

Hermon, D. 2014. Impacts of Land Cover Change on Climate Trend in Padang Indonesia. Indonesian Journal of Geography. Volume 46. Issue 2. p: 138-142. Fakultas Geografi Universitas Gajah Mada.

Hermon, D. 2017. Climate Change Mitigation. Rajawali Pers (Radjagrafindo).

Hermon, D., Putra Aprizon., and Oktorie, Olivia. 2018. Suitability Evaluation of Space Utilization Based on Enviromental Sustainability at The Coastal Area of Bungus Bay in Padang City, Indonesia. International Journal of GEOMATE. Volume 14. Issue 41. p: 193-202. Geomate International Society.

King, R.B. (1970). A Parametric approach to land system classification. Geoderma 4 (1), 37-46.

Lacate, D.S. (1969). Guidelines for bio-physical land classification. Department of Fisheries and Forestry, Canadian Forestry Service. Publication No. 1264. Ottawa. 61 pp.

Lillesand, T.M., Kiefer, R.W. (1979). Remote Sensing and Image Interpretation. John Wiley and Sons, New York. 612 pp.

Linton, D.L. (1951). The delimitation of morphological regions. In Stamp, L.D. and Wooldridge, S.W. (Eds.). London Essays in Geography. Longmans, Green and Co., London. pp. 199-217.

Mabbutt, J.A. (1968). Review of concepts of land classification. In Stewart, G.A. (Ed.) Land Evaluation. Papers of a CSIRO Symposium organised in cooperation with UNESCO 26-31 August 1968. Macmillan of Australia. pp.11-28.

Milne, G. (1935). Some suggested units of classification and mapping, particularly for East African Soils. Soil Research. 4, 183-198.

Mitchell, C. (1973). Terrain Evaluation. Longman, London. 221 pp. 
Mitchell, C.W., Perrin, R.M.S. (1966). The subdivision of hot deserts of the world into physiographic units. Intern. Arch. Photogrammetry. 16(4), 89-106.

Murdoch, G., Ojo-Atere, J., Colborne, G., Olomu, E.I. and Odugbesan, E.M. (1976). Soils of the Western State Savanna in Nigeria. Volumes 1, 2, 3 and Maps. Land Resource Study 23. Land Resource Division, Ministry of Overseas Development.

Oktorie, O. 2017. A Study of Landslide Areas Mitigation and Adaptation in Palupuah Subdistrict, Agam Regency, West Sumatra Province, Indonesia. Sumatra Journal of Disaster, Geography and Geography Education. Volume 1. Issue. 1. p: 43-49. Master Program of Geography Education.

Olson, G.W. (1974). Land classifications. Search: Agriculture (Agronomy 4). 4(7),3-33. Cornell University Agric. Exp. Stn., Ithaca.

Perrin, R.M.S., Mitchell, C.W. (1969). An appraisal of physiographic units for predicting site conditions in arid areas. Military Engineering Experimental Establishment. Report No. 1111, Volume 1. Christchurch, Hampshire, England. 313 pp.

Prokayev, V.I. (1962). The Facies as the basic and smallest unit in landscape science. Soviet Geography: Review and Translation. 3(6),21-29.

Sitorus, S.R.P. (1983). The Analysis of Soil Variability for Land Capability Assesment. Ph.D. Thesis. University of Sheffield, United Kingdom. 373 pp.

Soetanto. (1978). Aerial photography in Indonesia. Photogrammetria 34,79-87.

Solntsev, N.A. (1962). Basic problems in Soviet landscape science. Soviet Geography: Review and Translation. 3(6),3-15.

Storie, R.E. (1950). Rating soils for agricultural, forest and grazing use. Trans. 4th International Congress of Soil Science. 1,336-339.

Storie, R.E. (1950). Land classification as used in California for the appraisal of land for taxation purposes. Transactions 5th International Congress of Soil Science. 3,407-412.

Unstead, J.F. (1933). A system of regional geography. Geography 18,175-187.

Van Zuindam, R.A., Van Zuindam-Cancelado, F.I. (1979). Terrain Analysis and Classification using aerial photographs. ITC Textbook of photo-interpretation. Vol. VIII. Chapter 6. International Institute for Aerial Survey and Earth Sciences (ITC), Enschede, The Netherlands. 310pp. + Supplement 23 pp.

Vinogradov, B.V., Gerencluk, K.I., Isachenko, A.G., Raman, K.G., Tsesel'chuk, Yu. N. (1962). Soviet Geography: Review and Translation. 3(6),15-20.

Vink, A.P.A. (1975). Land Use in Advancing Agriculture. Springer-Verlag, Berlin, 394 pp.

Weiers, C.J. (1975). Soil classification and land valuation. Town and Country Planning. 43,390-393.

Wright, R.L. (1972). Principles in a geomorphological approach to land classification. Zeitschr. f. Geom. 16(4),351-373.

Wright, R.L. (1973). An examination of the value of site analysis in field studies in tropical Australia. Zeitschr. f. Geom. 17(2),156-184.

Wright, L.E., Zitzmann, W., Young K., and Googins, R. (1983). LESA-Agricultural land evaluation and site assessment . Journal of Soil and Water Conservation. 38(2),82-86.

Zonneveld, I.S. (1979). Land Evaluation and Land (scape) Science. Second Edition. ITS Textbook of photointerpretation Vol. VII Chapter VII. 4 ITC, Enschede, The Netherlands. 134 pp. 